\title{
An improved DAPI staining procedure for visualization of polyphosphate granules in cyanobacterial and microlagal cells
}

Krishna Ray ( $\sim$ kray91@gmail.com )

Krishna Ray's Lab (West Bengal State University), Department of Botany, Berunanpukuria, Malikapur, Barasat, Kolkata 700126, India

Chandan Mukherjee

Krishna Ray's Lab (West Bengal State University), Department of Botany, Berunanpukuria, Malikapur, Barasat, Kolkata 700126, India

\section{Method Article}

Keywords: DAPI staining, polyphosphate, confocal microscopy

Posted Date: July 7th, 2015

DOI: https://doi.org/10.1038/protex.2015.066

License: (c) (i) This work is licensed under a Creative Commons Attribution 4.0 International License. Read Full License 


\section{Abstract}

DAPI staining method is broadly used for the detection of polyphosphate granules in microbial cells. The present protocol modifies the existing methods for better detection of the granules with higher resolution on confocal microscopy, especially for cyanobacteria and microalgae. The approximate time required to prepare one slide for microscopic detection is around two and a half hours and to visualize it is around fifteen to thirty minutes.

\section{Introduction}

A widely accepted method for_in situ_ polyphosphate $\backslash$ (polyP) detection is fluorescence microscopy using a fluorochrome, 4', 6 - diamino-2-phenylindole $2 \mathrm{HCl} \backslash(\mathrm{DAPI})$ at high concentrations ranging from 3$50 \mu \mathrm{g} / \mathrm{ml}^{1}$. Interaction of polyP with DAPI shifts the emission maxima of the dye from $456 \mathrm{~nm}$ emitting blue fluorescence to $526 \mathrm{~nm}$ emitting bright yellow- green fluorescence ${ }^{2}$. The present protocol modifies the existing method of cell preparation by using Mcllvaine's buffer ${ }^{3}$ instead of PBS buffer ${ }^{4}{ }^{5}$ for more efficient microscopic detection of the polyP granules in cyanobacteria and microalgae _in vivo_. The use of PBS buffer greatly reduces the contrast and resolution during confocal microscopy as compared to Mcllvaine's buffer. It was also observed that the application of the dye to the specimen at concentrations greater than $25 \mu \mathrm{g} / \mathrm{ml}$ resulted in only blue light emission making the detection of polyP impossible.

\section{Reagents}

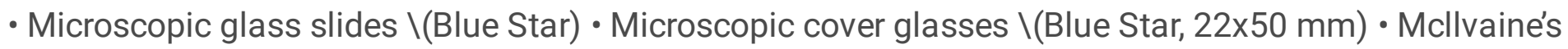
buffer preparation I. Stock solution A: $0.1 \mathrm{M}$ citric acid solution. Dissolve $4.2 \mathrm{~g}$ of citric acid $\backslash($ Merck, Cat. No. 61799705001730 ) in $200 \mathrm{ml}$ double distilled water II. Stock solution B: $0.2 \mathrm{M} \mathrm{Na}_{2} \mathrm{HPO}_{4}$ solution. Dissolve $22.7 \mathrm{~g}$ of $\mathrm{Na}_{2} \mathrm{HPO}_{4} \backslash$ (Merck, Cat. No. 1.06559.0500) in $800 \mathrm{ml}$ double distilled water III. Mix 2 parts of stock solution $A$ and 8 parts of stock solution $B$ to make $\mathrm{pH} 7.0$ buffer $\cdot$ Formaldehyde $\backslash$ (Merck, Cat No. 8.18708.1000) • Triton-X-100 \(HiMedia, Cat. No. MB031-100ML) • 4', 6 - diamidino-2-

phenylindoledihydrochloride \(DAPI) solution preparation I. Dissolve 2 mg DAPI \(Sigma-Aldrich, Cat. No. D9542) in $1 \mathrm{ml}$ Mcllvaine's buffer to prepare a main stock solution of concentration of $2 \mathrm{mg} / \mathrm{ml}$. Store it in dark at $-20^{\circ} \mathrm{C} \mathrm{II}$. Prepare working stock solution of the concentration of $20 \mu \mathrm{g} / \mathrm{ml}$ by diluting $10 \mu \mathrm{l}$ of the main stock solution with $990 \mu$ of Mcllvaine's buffer. Store it in dark at $-20^{\circ} \mathrm{C}$

\section{Equipment}

- Confocal microscope \(OLYMPUS 1X81 with FV 1000 software)

\section{Procedure}

1. Take $1 \mathrm{ml}$ of microalgal and cyanobacterial culture grown for 25 days at $28^{\circ} \mathrm{C}$ in $\mathrm{BG}-11 \backslash$ (non- $\mathrm{N}_{2}$ fixer medium) and BG-0 \( $\mathrm{N}_{2}$ fixer medium). 2. Centrifuge the samples at $2350 \mathrm{~g}$ for 5 minutes. Discard the 
supernatant. 3. Wash the cell pellet with $200 \mu \mathrm{l}$ Mcllvaine's buffer. 4. Fix the pellet with $200 \mu \mathrm{l}$ of $4 \%$ formaldehyde $\backslash$ (prepared in Mcllvaine's buffer) and incubate for 30 minutes. 5 . Wash again with the buffer. 6 . Make the cells permeable by treating them with $200 \mu \mathrm{l}$ of $0.3 \% \backslash(\mathrm{v} / \mathrm{v})$ Triton-X-100 solution $\backslash$ (prepared in Mcllvaine's buffer) for 5 minutes. Repeat washing with the buffer. 7. Mix the cells on the slide with $200 \mu$ of DAPI solution and incubate for 30 minutes in the dark. CRITICAL STEP: All the further steps including the present one should be strictly carried out in the dark. 8. Re-wash it gently with the buffer. CRITICAL STEP: Proper and gentle washing should be done to minimize the background noise due to the fluorescence of extra DAPI stain present on the slide during microscopy. 9. Dry the slides at room temperature in the dark. 10. Observe the slides under confocal microscope by setting the excitation filter at $370 \mathrm{~nm}$ and emission filter at $526 \mathrm{~nm}$.

\section{Timing}

Approximately two and a half hours will be required to prepare one slide for confocal microscopic observation. Visualization of one sample specimen may take around fifteen to thirty minutes.

\section{Troubleshooting}

1. The pH of the Mcllvaine's buffer should be 7.0 as the DAPI stain does not react with the polyphosphate granules even at the slight variation of $\mathrm{pH}$.

\section{Anticipated Results}

DAPI-stained polyphosphate granules present in the cyanobacterial and microalgal cells show bright yellow- green fluorescence at $526 \mathrm{~nm}$ upon observation under confocal microscope $\backslash$ (Figure 1) whereas the cells devoid of the granules emit a light blue fluorescence at $456 \mathrm{~nm}$.

\section{References}

1. Ryazanova, L._et al._ The early stage of polyphosphate accumulation in _Saccharomyces cerevisiae_: comparative study by extraction and DAPI staining. _Adv. Biosci Biotech._ ${ }^{\star \star 2}{ }^{\star \star}, 293-297 \backslash(2011) .2$. Tijssen, J.P._et al._ Localization of polyphosphates in _Saccharomyces fragilis_, as revealed by 4',6 diamidino-2-phenylindole fluorescence._Biochim Biophys Acta._ ${ }^{\star} 721^{\star \star}, 394-398 \backslash(1982)$. 3. DAPI Staining Protocol. Laboratory for Experimental Botany, University of Ljubljana, Slovenia. **http:// botanika.biologija.org/exp/protocols/DAPI-staining-protocol.pdf** $\backslash$ (accessed July 5, 2015). 4. Gunther, S. _et al._ Dynamics of polyphosphate-accumulating bacteria in wastewater treatment plant microbial communities detected via DAPI $\backslash\left(4^{\prime}, 6^{\prime}\right.$ - diamidino-2-phenylindole) and tetracycline labeling. _Appl. Environ. Microb._**75**, 2111-2121 \(2009). 5. Medeiros, L.C.S._et al._ Volutin granules of _Eimeria_ parasites are acidic compartments and have physiological and structural characteristics similar to acidocalcisomes. _J. Eukaryot. Microbiol._ ${ }^{\star \star 58 * \star}$, 416-423 \(2011). 


\section{Acknowledgements}

The authors acknowledge the help rendered in confocal microscopy by the DBT-IPLS Centre of University of Calcutta, West Bengal, India. The authors are also thankful to Dr. Chiranjib Pal, Department of Zoology, West Bengal State University, West Bengal, India for his help in fluorescence microscopy.

\section{Figures}

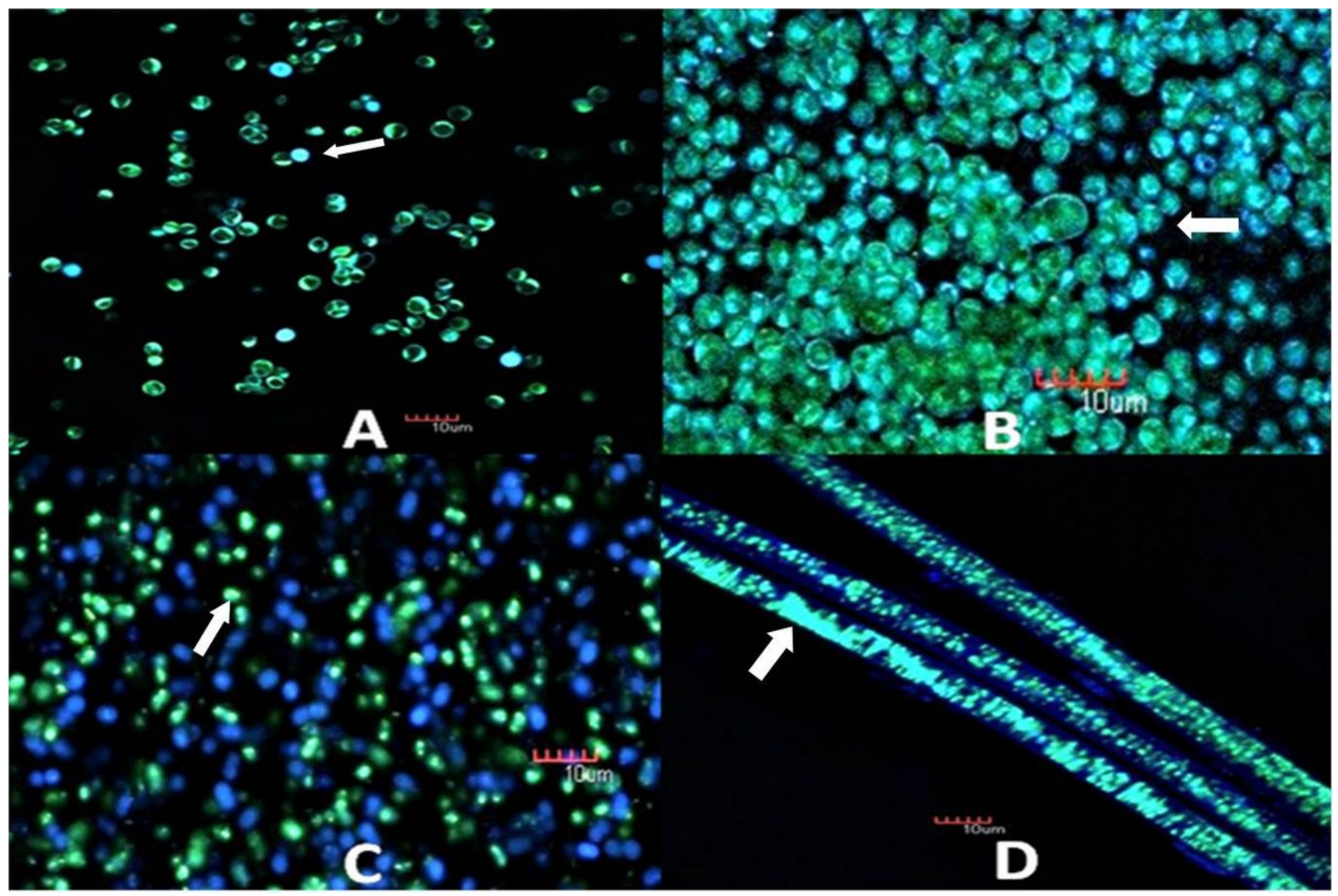

\section{Figure 1}

DAPI staining of polyphosphate granules present in the cyanobacterial and microalgal cells observed under confocal microscope White arrows indicate the presence of polyphosphate granules in the cells of: A) _Chlorella_sp. isolate 10.2; B)_Chlorella_sp. isolate H36; C) _Cyanobacterium_sp. isolate Fardillapur; D) _Lyngbya_sp. isolate 2.1. 